\title{
Endosso de celebridades e human brands no Instagram: estudo de caso da Coleção Fenty Puma by Rihanna
}

\author{
Rosana Vieira de Souza' \\ Gabriele Possebon²
}

\begin{abstract}
Resumo
O presente estudo tem como objetivo analisar de que forma se dá o endosso de celebridades na relação da cantora Rihanna com a coleção Fenty, da marca Puma, na plataforma Instagram. Para a base teórica da pesquisa, são apresentados autores que estudam sobre endosso de celebridades, human brands e sites de redes sociais. O estudo é baseado em um método qualitativo de pesquisa com o uso de análise de conteúdo (BARDIN, 2016). Ao analisar o caso Puma/Rihanna busca-se entender até que ponto o endosso de celebridade pode ser estendido para o conceito de human brands no contexto dos sites de redes sociais, adicionando desafios para a publicidade e a comunicação de marketing de modo geral.
\end{abstract}

Palavras-chave: Endosso de celebridades. Human brands. Instagram

\begin{abstract}
The present study intends to analyze how celebrity endorsement is presented in Rihanna's relationship with Fenty Collection by Puma, on the Instagram platform. For the theoretical basis of this research, we presented authors who study celebrity endorsement, human brands, and social networking sites. The study is based on a qualitative research method with the use of content analysis (BARDIN, 2016). In analyzing the Puma / Rihanna case, the aim is to understand to what extent celebrity endorsement can be extended to the concept of human brands in the context of social networking sites, adding challenges to advertising and marketing communication in general.
\end{abstract}

Keywords: Celebrity endorsement. Human brands. Instagram

\section{Introdução}

O presente artigo tem como tema o endosso de celebridades e as human brands, onde abordamos, como objeto empírico de investigação, a marca esportiva Puma e a cantora Rihanna. Khatri (2006) trata a personalidade como endorser ${ }^{3}$ do produto

\footnotetext{
1 Doutora em Ciências da Comunicação (Unisinos). souza.rovieira@gmail.com

2 Graduada em Publicidade e Propaganda pela Universidade Feevale/RS.

gabrielepossebon@gmail.com

3 Endorser: pessoa que endossa um produto ou serviço.
} 


\section{VOZES $_{\text {\&IÁLORO }}^{\mid}$}

Itajaí, v. 17, n. 02, jul./dez. 2018

anunciado, ou seja, uma celebridade com tanta autoridade em relação a um assunto que acaba "emprestando" sua credibilidade para o produto. Explorar a admiração do público, incluindo a celebração por figuras famosas, vem sendo usado como forma de anunciar produtos e serviços há muitas décadas, desde quando o endosso acontecia por meio do rádio (LEARS, 1994).

Entretanto, as relações entre celebridade, marca e consumidor vêm sendo impactadas, na última década, com o desenvolvimento da Web 2.0 e a mediação, cada vez mais presente, de plataformas digitais em rede. Os sites de redes sociais mudaram a forma como o público interage com as celebridades, pois o conteúdo passa a ter acesso muito mais rápido e sem fronteiras. A rede social Instagram, por exemplo, gerou uma mudança cultural e de comportamento, tanto para o público geral, quanto para as celebridades, já que o compartilhamento de informações é diário e em tempo real, contribuindo para maior confiança entre as partes (PIZA, 2012). O protagonismo dos sites de redes sociais na vida contemporânea traz oportunidades para a publicidade no sentido de propiciar novas formas de narrativas e apropriações destes ambientes digitais para a comunicação mercadológica.

Nesse sentido, este trabalho tem como problema de pesquisa os seguintes questionamentos: de que forma a mediação digital reconfigura o papel do endosso de celebridades na comunicação de marca? Como se dá o endosso de celebridades na relação da cantora Rihanna com a coleção Fenty da marca Puma na plataforma Instagram? Assim, o objetivo deste artigo é analisar de que forma se dá o endosso de celebridades na relação da cantora Rihanna com a coleção Fenty, da marca Puma, na plataforma Instagram. Além disso, pretendemos: (1) analisar quais elementos de endosso de celebridades estão presentes na relação entre Puma e Rihanna; (2) analisar quais elementos de uma human brand estão presentes na relação entre Puma e Rihanna; e (3) identificar como essa relação é exposta no site de rede social Instagram.

A importância de analisar o caso Puma e Rihanna é para entender até que ponto o endosso de celebridade pode ser estendido para o conceito de human brands. A importância deste estudo, para a publicidade e suas narrativas, está em entender como práticas clássicas da comunicação, como é o caso do endosso de celebridade, são reconfiguradas ao incorporar um novo estilo de comportamento do público consumidor mediado por plataformas digitais, tais como os diversos sites de redes sociais.

Para poder resolver o problema de pesquisa e atender aos objetivos definidos, foi escolhido seguir com uma pesquisa básica com estudo exploratório, desenvolvendo uma pesquisa de natureza qualitativa, através de um estudo de caso da construção da coleção Fenty Puma by Rihanna a partir das narrativas contidas nas postagens da cantora no Instagram. 


\section{Endosso de Celebridades versus Celebridades como human brands}

As celebridades são, em geral, vistas como heroínas e heróis, por suas personalidades e trabalhos realizados. Segundo Shimp (2003), o uso de celebridades é uma das principais ferramentas de divulgação da publicidade norte-americana e são, com frequência, escolhidas nos meios esportivo ou do entretenimento. Essas personalidades têm o poder de influenciar na decisão de compra do consumidor e também de criar experiências. A prática do uso de celebridades na publicidade é definida pelo termo "endosso de celebridade", onde a celebridade empresta seu nome e imagem a uma marca a fim de anunciar um produto (KHATRI, 2006).

Para McCracken (2015), o processo de endosso depende da transferência de significados, em uma perspectiva em que a efetividade do endosso depende das características simbólicas da celebridade endossadora. Isto significa que a celebridade transfere significado ao bem de consumo, e do bem de consumo ao consumidor. Segundo Belch e Belch (2014), ainda há outros dois modelos que antecedem o de McCracken, o modelo de fonte de credibilidade e de fonte de atratividade.

Para Freire e Senise (2011) a credibilidade transferida ao produto é a peça necessária para persuadir o consumidor a comprá-lo. Para que celebridade e marca sejam vistas como uma unidade pelo consumidor, busca-se um endossante que represente o posicionamento da marca, ou seja, não basta a celebridade ter alto poder de alcance e de engajamento, ela também precisa pertencer de alguma forma ao universo da marca endossada.

Alguns autores, como Spry, Pappu e Cornwell (2011), já deixaram de ver a celebridade somente como endosso de credibilidade que leva à venda. $\mathrm{O}$ vínculo entre marca e celebridade faz parte da personificação da marca e da sua percepção pelo consumidor. Centeno e Wang (2016) tratam como human brands qualquer pessoa famosa que é usada como ferramenta de marketing, cujas ações geram produtos, que geram identidades de marca. De forma similar, Holmes e Redmond (2014) apresentam a perspectiva de que as celebridades são human brands, suas performances dentro ou fora do palco, online ou offline, públicas ou privadas, são experiências de marca e de marketing. Suas escolhas cotidianas e seus valores são privados, mas apresentados em público. Essas ações criam uma identidade de marca. Consequentemente, a identidade de uma human brand vende produtos por meio do endossamento e da persuasão, transferindo qualidades pessoais para dar vida a uma marca.

Na visão de Kerrigan et al (2011, p. 1511):

O endosso de celebridade, embora seja uma consideração legítima para os profissionais de marketing, aborda a celebridade de uma forma limitada; a celebridade "tem" o status de celebridade e concede isso a 


\section{VOZES $_{\text {\&IÁLORO }}^{\mid}$}

Itajaí, v. 17, n. 02, jul./dez. 2018

uma marca/produto com o objetivo de melhorar a posição deste produto no mercado.

Quando uma celebridade endossa uma marca e seus posicionamentos são similares, ambas acabam transferindo significados. A personalidade da celebridade passa a ser associada à marca, gerando uma identificação e assim, projetando uma identidade viva para a marca. O modelo de transferência de significados de McCracken (1989) pode ser visto em Centeno e Wang (2016), onde trazem a celebridade como personalidade que transfere significado como endossante e apresentam a transferência de significados como parte fundamental do processo de endosso.

Para Centeno e Wang (2016), as celebridades são identidades vivas, ou seja, são pessoas que são percebidas como uma marca, que cocriam suas marcas. As human brands atuam nas redes sociais de acordo com suas personalidades, e é nas redes sociais que a interação com os fãs e consumidores acontece. Os autores abrem uma discussão interessante, de que os consumidores veem as celebridades que atuam como human brands como algo presente em suas vidas, já que podem expressar suas opiniões por meio de comentários e curtidas em diferentes plataformas. Para Lunardo, Gergaud e Livat (2015), uma celebridade é considerada uma human brand quando ela é fator de interesse para o mercado.

Thompson (2006) buscou estudar o apego do público consumidor para com uma human brand e como esses consumidores podem ser considerados importantes acessórios para as human brands. Assim, segundo Thompson, uma celebridade, seja ela um ator, um cantor, um atleta, tem ativos intangíveis: um nome, uma reputação, uma credibilidade e uma imagem. Esses atributos podem ser combinados e transformados em uma marca. $\mathrm{O}$ autor cita Oprah Winfrey ${ }^{4}$ como exemplo de como grandes empresas investem em human brands para aumentar sua ligação com o consumidor.

\section{Sites de redes sociais como ambiente para novas formas de interação}

A Web passou por uma significativa mudança. Até então sua função se limitava a um grande portal estático, disponibilizando informações, mas com a Web 2.0 em meados dos anos 2000, torna-se ambiente para interação e propagação de conteúdos gerados pelo usuário comum. A Web 2.0 surge como plataforma, onde se popularizam os blogs, os sites

4 Uma das mais conhecidas apresentadoras do mundo, com o programa The Oprah Winfrey

Show, o talk show com maior audiência dos EUA. 


\section{VOZES $_{\text {\&IÁLORO }}^{\mid}$}

Itajaí, v. 17, n. 02, jul./dez. 2018

de redes sociais e de compartilhamento de conteúdos e os mecanismos de busca (TORRES, 2009).

O uso dos sites de redes sociais mudou a forma como acontece a comunicação social em geral e ainda mais entre marca/consumidor, herói/admirador. Os sites de redes sociais ampliaram o alcance da interação, onde o público deixa de ser somente expectador e passa a participar ativamente de comunidades. Nas redes sociais vemos uma cultura de emergência, onde se preza pela instantaneidade das informações e, nesse novo formato de interação, ser percebido é o maior objetivo, segundo Jenkins (2009). A produção e disseminação de conteúdo por marcas para fins de divulgação e comunicação com o consumidor se torna cada vez mais comum.

Após essa transformação para a internet como plataforma interativa, temos um aumento da participação coletiva entre os usuários. A Web 2.0 se refere a uma mudança comportamental na internet. É a partir deste ponto que o usuário passa de apenas espectador para também produtor de conteúdo. Botsman (2016) fala sobre como a tecnologia está mudando a confiança dentro da organização social: para a pesquisadora, a confiança em empresas não é algo funcional para a era digital, e então a confiança é desviada de instituições para pessoas. A influência da tecnologia em nossas vidas faz com que, segundo a autora, deixemos de confiar em instituições e passemos a confiar em estranhos. Por "estranhos" podemos pensar em pessoas que conhecemos apenas por meio de plataformas digitais, tais como as celebridades.

\section{Instagram}

O Instagram é uma plataforma de compartilhamento de fotos e vídeos onde também é possível comentar e curtir as fotos postadas na rede. O Instagram foi criado em 2010, por Mike Krieger e Kevin Systrom, que inicialmente era chamado de Burbn e tinha outra estrutura, considerada muito complicada pelos criadores. Por ser um aplicativo com facilidade de uso e diversas opções de postagens, o Instagram tem mais de 500 milhões de atividades por dia.

Figuras públicas possuem milhões de seguidores em seus perfis do Instagram. A personalidade com maior número de seguidores na plataforma, atualmente, é a cantora e atriz Selena Gomez, com mais de 127 milhões de seguidores; outras celebridades, como o jogador de futebol Cristiano Ronaldo, as cantoras Ariana Grande, Beyoncé, Taylor Swift, e a empresária Kim Kardashian, também têm mais de 100 milhões de seguidores na rede social'.

\footnotetext{
5 Segundo dados do Portal G1. Disponível em: <https://g1.globo.com/tecnologia/noticia/instagram-tem-800-milhoes-de-usuarios-ativos-pormes-e-500-milhoes-por-dia.ghtml>. Acesso em: maio de 2018.

6 Segundo dados da revista L'Officiel. Disponível em: <

https://www.revistalofficiel.com.br/moda/a-celebridade-com-o-maior-numero-de-seguidoresdo-instagram>. Acesso em: maio de 2018.
} 


\section{VOZES \\ DIÁLOGO}

Itajaí, v. 17, n. 02, jul./dez. 2018

Assim, pode-se dizer que os sites de redes sociais e suas estruturas estão sempre mudando e fazendo surgir novos padrões. A mediação pelo computador, por exemplo, gerou outras formas de estabelecimento de relações sociais. Para Recuero (2009), as pessoas se adaptaram aos novos tempos de relações virtuais, utilizando as redes sociais para formar novos padrões de interação e criar novas formas de se relacionar e novas organizações sociais.

\section{Procedimentos metodológicos}

Para dar conta dos objetivos propostos, optamos pela realização de uma pesquisa de natureza exploratória e qualitativa. A partir da observação da plataforma Instagram oficial da cantora Rihanna, no período entre dezembro de 2014 e abril de 2018, foram observadas todas as postagens referentes à coleção Fenty da Puma, que somam um total de 174 publicações até o dia 30/04/2018. Neste primeiro momento, buscou-se identificar o universo da pesquisa a partir do qual foi, posteriormente, selecionado o período de análise da relação da cantora com a marca a partir das postagens na plataforma. Ao buscarmos todas as postagens da Rihanna, na plataforma Instagram, referentes à Puma, identificamos cinco momentos:

$1^{\circ}$ momento: início da interação com a Puma. Em 2014, Rihanna começa a mencionar a Puma em suas publicações e aparece usando itens da marca;

$2^{\circ}$ momento: lançamento do tênis "The Creeper" em setembro 2015;

$3^{\circ}$ momento: lançamento da primeira coleção Fenty Puma by Rihanna;

$4^{\circ}$ momento: no ano de 2017 são lançadas mais duas coleções, SS17 (primavera/verão 2017) e a coleção AW17 (outono/inverno 2017);

$5^{\circ}$ momento: lançamento da coleção SS18, primavera/verão 2018.

Na Figura 1, a seguir, sintetizamos, em uma linha do tempo, os momentos referentes às coleções Fenty Puma by Rihanna. 


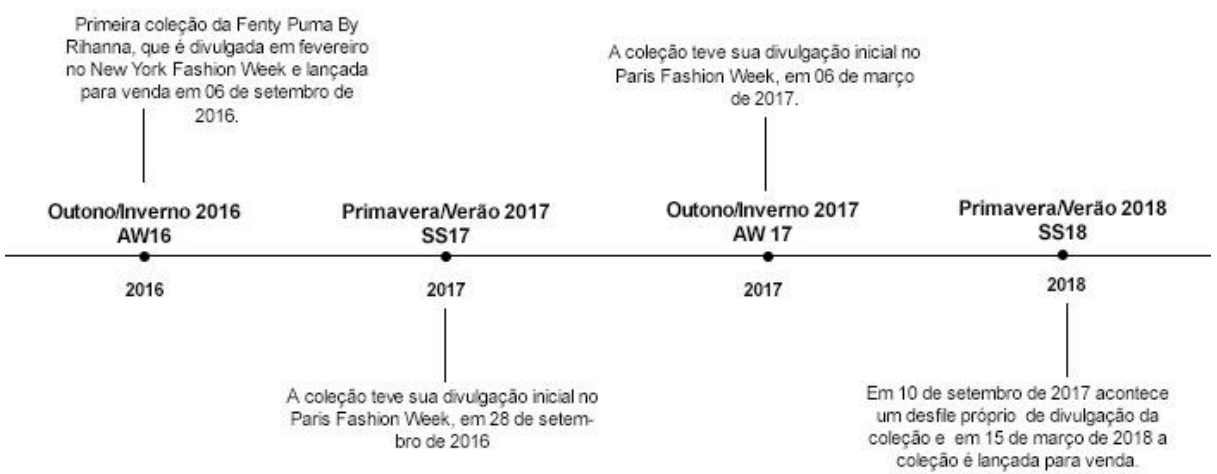

Fonte: as autoras.

O material analisado foi a coleção $\mathrm{S} / \mathrm{S} 18$, investigando as 13 postagens referentes à coleção, publicadas entre 10 de setembro de 2017 e 15 de março de 2018. Essa foi a última coleção lançada pela Fenty Puma by Rihanna e foi a primeira coleção a ter um show de divulgação, assim como dois vídeos.

Para realizar a análise dessas publicações, o conteúdo coletado foi descrito e interpretado. Para isso, optamos pela metodologia interpretativa da análise de conteúdo, pelo método de Bardin (2016). A análise de interpretação está diretamente ligada ao processo de busca pela compreensão do conteúdo, por um conjunto de técnicas de análise, através de processos e objetivos que embasam a descrição do conteúdo. Os dados coletados são organizados em categorias de unidades, assim é possível a descrição de cada categoria por conjuntos de similaridades pertinentes ao conteúdo (BARDIN, 2016).

Ao analisarmos as postagens referentes à coleção SS18, buscou-se separar essas publicações por categorias, onde foi possível identificar três, as quais assim nominamos: (1) personalidade de linguagem; (2) marca corporificada; e (3) interação com a marca. A seguir, apresentaremos as três categorias encontradas e uma publicação representando cada categoria.

\section{Análise das publicações no Instagram referentes à coleção Fenty Puma by Rihanna}




\section{VOZES}

Itajaí, v. 17, n. 02, jul./dez. 2018

Buscou-se relacionar as categorias com os conceitos de endosso de celebridade e human brands. No caso da presente pesquisa, os dados foram categorizados de acordo com as semelhanças com os temas abordados na fundamentação teórica.

Quadro 1-Categorias de análise

\begin{tabular}{|c|l|}
\hline Categoria & \multicolumn{1}{|c|}{ Descrição } \\
\hline Personalidade linguística & $\begin{array}{l}\text { A cantora Rihanna manifesta sua personalidade e cultura na forma como se } \\
\text { refere à coleção, da mesma forma que faz em suas outras publicações no } \\
\text { Instagram e como canta em suas músicas. A personalidade da cantora é } \\
\text { explorada em sua escrita para o público. }\end{array}$ \\
\hline A marca corporificada & $\begin{array}{l}\text { Nesta categoria temos as publicações que mostram o uso da coleção Fenty } \\
\text { Puma By Rihanna pela própria cantora, apresentando como Rihanna "veste" } \\
\text { a coleção. }\end{array}$ \\
\hline Interação de marca & $\begin{array}{l}\text { Posicionamento de Rihanna e da marca Puma nas fotos oficiais de divulgação } \\
\text { da coleção Fenty Puma By Rihanna, analisando a interação de ambas na } \\
\text { composição do conteúdo divulgado. }\end{array}$ \\
\hline
\end{tabular}

Fonte: as autoras.

A seguir, apresentamos a análise de três publicações, cada uma representando uma categoria.

\section{Personalidade linguística}

Esta categoria evidencia a personalidade da cantora em sua escrita para o público. Na publicação analisada temos como contexto o fashion show , que aconteceu no dia 10 de setembro de 2017, um desfile de divulgação da coleção SS18, organizado por Rihanna e Puma. Autores como McCracken (2015) e Freire e Senise (2011) destacam que, em uma relação de endosso, a personalidade da celebridade endossante está presente no produto e também acaba sendo transferida para a marca. Na imagem a seguir, vemos como a cantora Rihanna coloca suas características de linguagem e de comportamento na legenda da publicação.

7 Fashion Show: desfile de moda onde são apresentadas as novas tendências da indústria. 


\section{VOZES $_{\text {\&IÁLORO }}^{\mid}$}

Itajaí, v. 17, n. 02, jul./dez. 2018

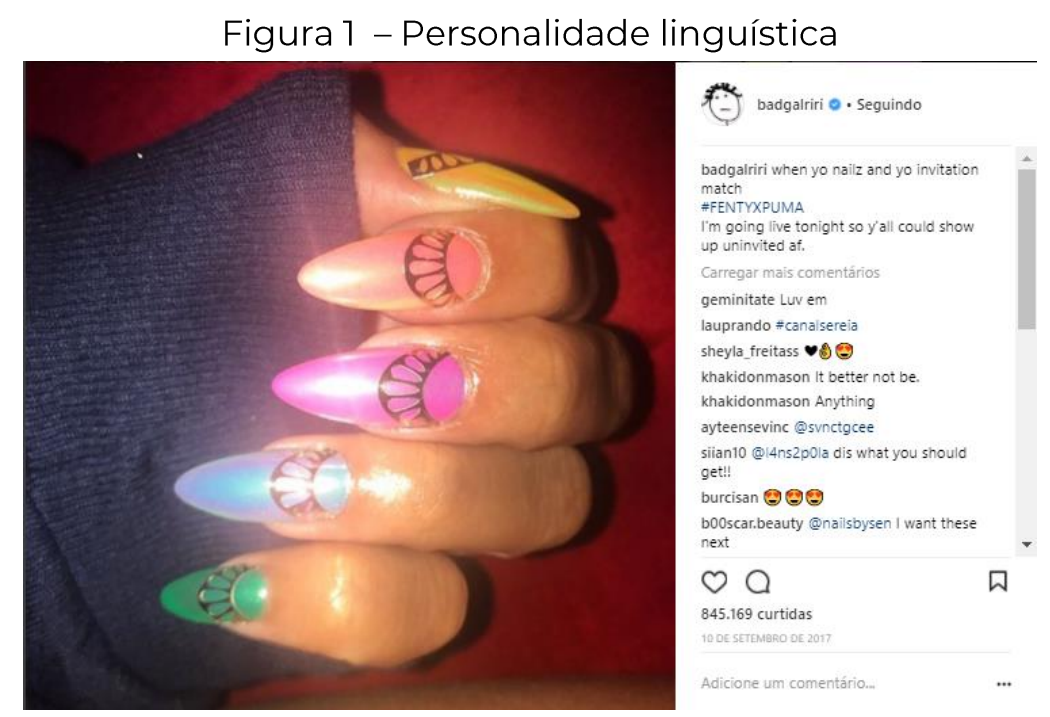

Fonte: coleta de dados: Instagram oficial de Rihanna (2017)

$\mathrm{Na}$ imagem temos as unhas da cantora Rihanna pintadas nas cores do layout de divulgação do fashion show e na legenda temos: "When yo naliz and yo invitation match \#FENTYxPUMA I'm going live tonight so y'all could show up uninvited af". Rihanna escreve de forma totalmente informal e com gírias que usa em seu dia a dia, como "yo" que é uma abreviação para your (seu/sua). É possível perceber sua personalidade também nas gírias "af" e "naliz", esta última sendo uma expressão para nails, que significa unhas em inglês. A gíria "af” aparece também em outras publicações de Rihanna que não são relacionadas à Puma, como na seguinte legenda: "employee of the month af !", de uma publicação feita no dia 12 de fevereiro de 2018.

As mesmas expressões de linguagem são encontradas nas músicas da Rihanna, como na letra de Kiss it Better, onde temos "But ya take me back; When I look you in yo eye"; na letra da música All Of The Lights, parceria com o rapper Kanye West, temos "Extra bright, I want y'all to see this".

Para Centeno e Wang (2016), as human brands atuam nas redes sociais de acordo com suas personalidades, e é por isso que a interação com os fãs e consumidores se torna tão próxima. A cantora manifesta sua personalidade e cultura na maneira como se refere à coleção, da mesma forma que faz em suas outras publicações no Instagram e como canta em suas músicas. Rihanna representa um determinado grupo social e é representante da cultura deste grupo. 


\section{VOZES $_{\text {\&IÁLORO }}^{\mid}$}

Itajaí, v. 17, n. 02, jul./dez. 2018

\section{A marca corporificada}

Nesta categoria buscamos analisar o uso da coleção Fenty Puma By Rihanna pela própria cantora, fora de imagens oficiais de divulgação. A publicação a seguir é referente ao fashion show e mostra a cantora chegando ao evento. Iremos analisar a Figura 3 e entender como a cantora Rihanna se comporta em relação à marca Puma.

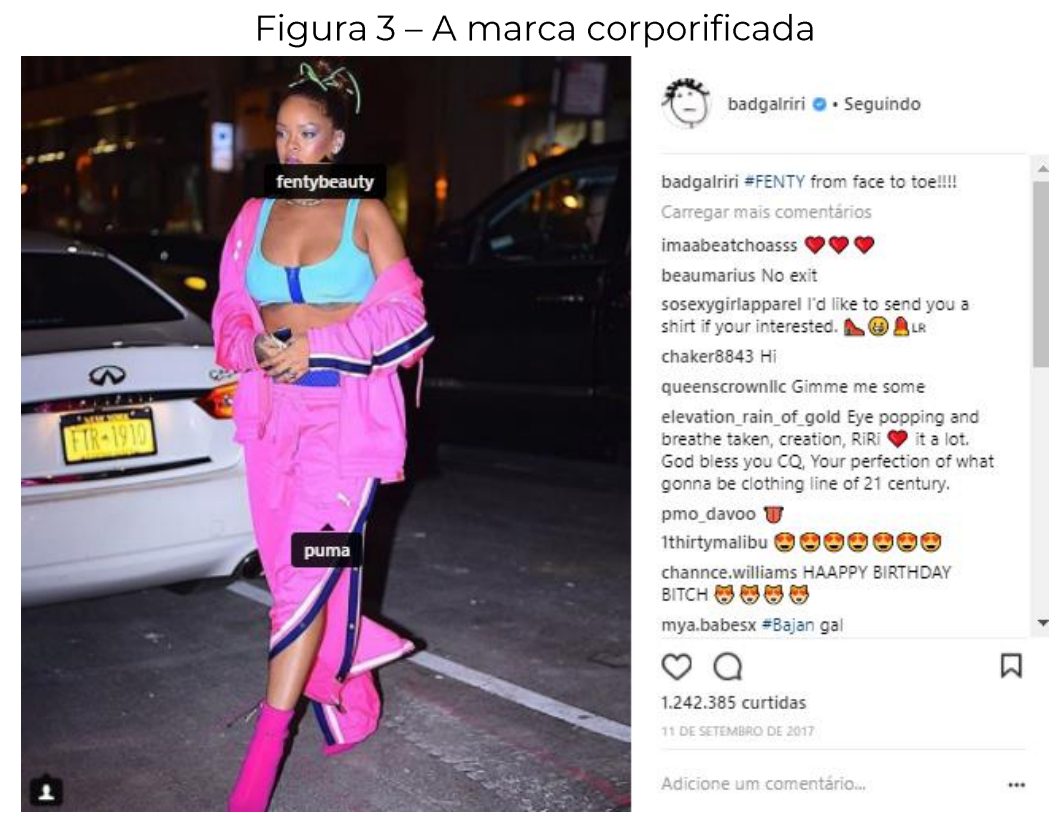

Fonte: coleta de dados: Instagram oficial de Rihanna (2017)

Na Figura 3, temos a publicação feita por Rihanna em seu perfil do Instagram no dia 11 de setembro de 2017. Na imagem, Rihanna está vestindo as peças que fazem parte da coleção SS18, casaco, blusa, calça e bota. As cores das peças são as mesmas cores do layout de divulgação do fashion show, que permite a identificação da marca. Além disso, Rihanna marca na publicação o perfil oficial da Puma no Instagram, para destacar de onde vêm as peças. A cantora faz referência também a sua marca de cosméticos, Fenty Beauty, e destaca o uso da sua própria linha de maquiagem. Na legenda da publicação, Rihanna escreve "\#FENTY from face to toe", em tradução: “\#FENTY do rosto aos dedos dos pés". Com essa descrição, entendemos que a cantora está usando sua própria marca da cabeça aos pés, relembrando que Fenty é o sobrenome de Rihanna.

Na Figura 3 também vemos que Rihanna vai além de emprestar seu nome ao produto, ela é o "produto" e é a representação viva da coleção Fenty Puma By Rihanna. A partir disso, podemos refletir sobre até que ponto as visões mais tradicionais em torno do conceito de endosso de celebridade são suficientes para explicar essa relação.

Uma human brand pode ser vista como parte de uma das várias operações de um conceito mais amplo de marca. A partir da interpretação do conteúdo e do contexto desta 


\section{VOZES}

Itajaí, v. 17, n. 02, jul./dez. 2018

categoria, vemos Rihanna como uma marca viva, uma human brand, que junto com a Puma, em uma relação de co-branding, trabalha na criação e divulgação da coleção Fenty Puma By Rihanna.

\section{Interação com a marca}

Nesta terceira categoria analisamos uma foto oficial de divulgação da coleção SS18, que foi compartilhada por Rihanna em seu perfil do Instagram. Esta postagem foi publicada no dia 28 de fevereiro de 2018 e faz parte do segundo momento de divulgação da coleção, que é a disponibilização para o público (Figura 4).

\section{Figura 4 - Interação com a marca FENTY Puma}
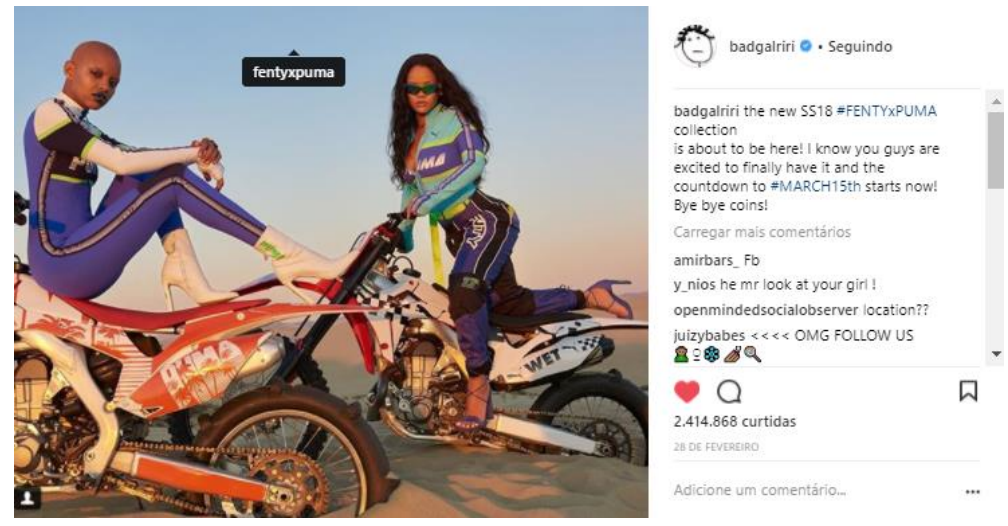

Fonte: coleta de dados: Instagram oficial de Rihanna (2018)

$\mathrm{Na}$ imagem, Rihanna aparece junto da modelo Slick Woods, que está presente também nas publicações referentes à Fenty Beauty. As fotos seguem a temática de motocicletas, com dunas e areia, como é retratado também no fashion show que apresentamos na categoria anterior. Ao analisar a imagem, percebe-se que Rihanna não é o destaque da composição da imagem, ela aparece em harmonia com a modelo Slick Woods, igualmente posicionadas, sem hierarquia. Essa composição é muito diferente dos conceitos propostos para o endosso de celebridade e, também, o oposto do que costuma ser foi feito na publicidade. Fonseca e Borges (2006) abordam o valor da figura da celebridade e apontam que, muitas vezes, a celebridade ultrapassa o valor da marca e cria um valor para o produto, fazendo com que a celebridade seja o principal fator de venda e desejo daquele produto. A julgar pelo fato de a coleção levar o nome de Rihanna, entendemos que ela é o principal fator de venda; porém, a forma de expor essa relação entre marca e celebridade muda. Nesta categoria podemos observar Rihanna exposta, na composição da imagem, como igual à Puma. 


\section{VOZES $_{\text {\&IÁLORO }}^{\mid}$}

Itajaí, v. 17, n. 02, jul./dez. 2018

\section{Interpretação dos contextos}

O modelo de transferência de significados de McCracken (1985) implica que a celebridade transfere significado ao bem de consumo e, do bem de consumo ao consumidor. O modelo de McGuire (1985) afirma que a mensagem depende da familiaridade e similaridade da fonte para que seja eficaz.

Todos os modelos podem ser alusivos à relação de Rihanna com a Puma. Nas três categorias que emergem a partir da observação das postagens no Instagram da cantora, vimos conceitos que foram relacionados ao endosso de celebridades e também à human brand. Com as mudanças de comportamento possibilitadas pela Web 2.0 e uma nova forma de produção de conteúdo e, por consequência, as formas de interação com eles, podemos perceber também uma mudança de comportamento na relação de endosso de celebridade. Isso nos leva a entender que o conceito de endosso de celebridades vem se transformando, e seu entendimento na ambiência de outros meios de comunicação já não é suficiente para abordar uma relação como a de Rihanna e Puma, que é construída pela mediação das plataformas digitais.

Com essa nova cultura de consumo, a partir da Web 2.0, as pessoas querem ouvir e ver as marcas, acreditando mais no que pessoas comuns falam do que nas instituições. Segundo Botsman (2016), o depósito de confiança em empresas não foi feito para a era digital, por isso a tecnologia está transferindo a confiança para as pessoas e tirando das instituições. Podemos incorporar este pensamento para o caso das human brands: Rihanna é uma celebridade que se apresenta como uma pessoa comum para seu público, com interesses e personalidades que, em algum ponto, assemelham-se.

\section{Considerações Finais}

Durante a contextualização dos temas abordados no artigo, endosso de celebridade e human brands, percebemos que para entender como essa relação era exposta na plataforma Instagram, precisávamos buscar discutir, brevemente, o contexto da Web 2.0 e de que modo este caracteriza uma mudança na exposição, compartilhamento e consumo da informação.

A mudança de comportamento e de interação entre marca e público afetou a forma como comunicamos uma marca. As relações passam a ser mais próximas de um contato real e assumem certa exigência vinda do público. Falamos em exigências pois, a partir do momento em que uma celebridade ou uma marca passa a gerar conteúdo para o público, ele exige ver veracidade e autenticidade no que é entregue a ele. A celebridade passa a 


\section{VOZES $_{\text {\&IÁLORO }}^{\mid}$}

Itajaí, v. 17, n. 02, jul./dez. 2018

entregar, de forma muito íntima, uma representação cultural, que é consumida pelos usuários.

A partir da análise das três categorias, conclui-se que human brands constituem uma evolução dos conceitos de endosso de celebridade. Percebe-se que o endosso de celebridade não é suficiente para entender uma relação como a de Rihanna e Puma, visto que a celebridade participa como representante viva do produto, com símbolos próprios, personalidade e características de um contexto social.

Identificou-se a mudança de comportamento na Web como um possível influenciador desta evolução de conceitos, devido ao contexto social que estamos inseridos e como a comunicação de uma marca sofreu alterações no decorrer dos anos, motivada pela grande participação do público. Um caminho a ser seguido, a partir deste artigo, seria o aprofundamento no estudo de comportamento em sites de redes sociais e avaliar como a publicidade recebe esse impacto em outros contextos e casos. Abordar a confiança como pesquisa futura, através dos sites de redes sociais, nos daria um bom direcionamento na compreensão de como as human brands participam do relacionamento entre marca e público.

Acreditamos que as características de endosso de celebridade e as de human brands foram identificadas na relação do caso investigado. Vemos que a coleção Fenty tem uma identidade resultante da junção de outras duas identidades, de Rihanna e da Puma. Mais do que isso, percebemos a internet como possível influência para a evolução e ampliação de conceitos publicitários. A Web 2.0 provocou mudanças de comportamento que afetam tanto público quanto marca. Os conceitos de human brands e endosso de celebridade se complementam, aprofundando o entendimento deste processo de co-branding e, consequentemente, ampliando nossa percepção quanto ao uso de celebridades na comunicação.

\section{Referências}

BARDIN, Laurence. Análise de Conteúdo. São Paulo: Edições 70, 2016.

BELCH, A. Michael; BELCH, E. George. Propaganda e Promoção: uma perspectiva da Comunicação Integrada de Marketing. São Paulo: Mcgraw Hill Bookman, 2014.

BOTSMAN, Rachel. We've stopped trusting institutions and started trusting strangers. $\quad 2016 . \quad$ TED, Disponível em: <https://www.youtube.com/watch?v=GqGksNRYu8s>. Acesso em: 25 de maio, 2018.

CENTENO, Dave; WANG, Jeff. Celebrities as human brands: an inquiry on stakeholder-actor co-creation of brand identities. Journal of Business Research, v. 74, p. 133-138, 2016. 


\section{VOZES \\ ¿'DIÁLOGO}

Itajaí, v. 17, n. 02, jul./dez. 2018

FONSECA, Pedro Baumgratz Tahan; BORGES, Admir Roberto. O testemunhal das celebridades da TV como gerador de credibilidade e venda de produtos. Belo Horizonte: UNIBH, 2006.

FREIRE, Otávio; SENISE, Diego. Percepção de celebridades do esporte. Organicom São Paulo, v.15, n. 8, 2011.

HOLMES, S.; REDMOND, S. Socialising celebrity. Celebrity studies, v. 5, n. 3, p. 223-224, 2014.

JENKINS, Henry. Cultura da convergência. 2. ed. São Paulo: Aleph, 2009.

KAPFERER, Jean Noel. As marcas, capital da empresa: criar e desenvolver marcas fortes. Porto Alegre: Bookman, 2003.

KERRIGAN，F.; BROWNLIE，D.; HEWER， P.; DAZA-LETOUZE，C. "Spining" Warhol: Celebrity brand theoretics and the logic of the celebrity brand. Journal of Marketing Management, p. 1504-1524, 2011.

KHATRI, Paul. Celebrity endorsement: a strategic promotion perspective. Indian Media Studies Journal, v. 1, n. 1, Jul.-Dec. 2006.

LEARS, Jackson. Fables of abundance: A cultural history of advertising in America. New York: Basic Books, 1994.

LUNARDO, R.; GERGAUD, O.; LIVAT, F. Celebrities as human brands: an investigation of the effects of personality and time on celebrities' appeal. Journal of Marketing Management, v. 5 n. 6, p. 685-712, 2015.

McCRACKEN, Grant. Who is the celebrity endorser? Cultural foundations of the endorsement process. Journal of Consumer Research, v.16, n. 2, dec. 1989.

Cultura e consumo. Rio de Janeiro, RJ: Mauad Editora Ltda, 2015.

McGUIRE, W. J. Attitudes and attitude change. Handbook of Social Psychology. New York: Random House, 1985.

MORAES, Marcela. Entertainment celebrity human brands: the complex role of celebrities' attributes and consumer-celebrity relationships upon consumers' aspirations and buying behaviour. $\mathrm{PhD}$ Thesis, Murdoch University, 2016. Disponível em: $<$ http://researchrepository.murdoch.edu.au/id/eprint/34871/>. Acesso em: 15 maio de 2018.

PIZA, Mariana Vassalo. O fenômeno Instagram: considerações sobre a nova perspectiva tecnológica. Brasília: Universidade de Brasília, 2012.

RECUERO, Raquel. Redes Sociais na Internet. Porto Alegre: Meridional, 2009.

SHIMP, A. Terence. Propaganda e promoção: aspectos complementares da comunicação integrada de marketing. Porto Alegre, RS: Bookman, 2002.

SPRY, Amanda; PAPPU, Ravi; CORNWELL, T. Bettina. Celebrity endorsement, brand credibility and brand equity. European Journal of Marketing, v. 45, n. 6, p. 882-909, 2011. 


\section{VOZES $_{\text {\&IÁLORO }}^{\mid}$}

Itajaí, v. 17, n. 02, jul./dez. 2018

THOMPSON, Matthew. Human brands: investigating antecedents to consumers' strong attachments to celebrities. Journal of Marketing, v. 70, July, p. 104-119, 2006.

TORRES, C. A bíblia do marketing digital: tudo o que você queria saber sobre marketing e publicidade na internet e não tinha a quem perguntar. São Paulo: Novatec, 2009 . 